\title{
UNIFORMIDADE DE DISTRIBUIÇÃO DE ÁGUA EM PIVÔ CENTRAL
}

\author{
Fernando França da Cunha' ${ }^{1}$, Gustavo Haddad Souza Vieira², José Antônio Rodrigues de Souza ${ }^{3}$, \\ Rafael Oliveira Batista ${ }^{4}$, Marcelo Rossi Vicente ${ }^{5}$
}

\begin{abstract}
RESUMO
Dentre os sistemas de irrigação existentes, o pivô central merece destaque por ocupar grandes áreas e consumir um grande volume de água. Diante disso, a utilização de equipamentos mais eficientes é uma busca constante, havendo necessidade de melhoria das metodologias existentes para sua avaliação. A presente pesquisa busca propor uma nova metodologia para determinar a uniformidade de distribuição de água por pivôs centrais. Foram utilizadas áreas irrigadas de 40, 60, 80, 100 e 120 ha, e em cada uma delas, avaliados dez pivôs centrais. Os tratamentos foram compostos de: pluviômetros equidistantes com o coeficiente de uniformidade de Christiansen (CUC) calculado conforme Christiansen (1942), modificado por Heermann e Hein (1968) (Método 1); pluviômetros instalados de forma que cada um representasse uma área amostral de 0,5 ha com o CUC calculado conforme Christiansen (1942) (Método 2); e (Métodos 3, 4, 5, 6 e 7): idem método 2, porém com coletores instalados, de forma que cada um representasse área amostral de 1, 2, 3, 4 e 5 ha, respectivamente. Obteve-se a área adequadamente irrigada (AAI) para obtenção do coeficiente de regressão da reta para cada avaliação. A determinação da uniformidade de pivôs centrais pelo método 2 foi a metodologia que mais se relacionou com o conceito de AAI, seguida das metodologias 1 e 3. Para pivôs centrais de tamanhos de 40, 60, 80, 100 e 120 ha, recomendam-se testes de uniformidade com coletores representando áreas amostrais máximas de até 1,0;1,1;1,3;1,4 e 1,6 ha, respectivamente.
\end{abstract}

Palavras-chave: área adequadamente irrigada, coeficientes de uniformidade, eficiência de irrigação, irrigação por aspersão.

\section{ABSTRACT \\ UNIFORMITY OF WATER DISTRIBUTION BY CENTRAL PIVOTS}

Among the existing irrigation systems, central pivots occupy extensive areas and consumes large amount of water. Thus, there is a constant search for more efficient use of such equipment requiring improvement of existing evaluation methods. This study proposes a new method to evaluate the uniformity of water distribution by central pivots. Areas of 40, 60, 80, 100 and 120 ha irrigated with central pivots, totaling 50 systems were evaluated. The treatments were: pluviometers with the Christiansen Uniformity Coefficient (CUC) calculated according to Christiansen (1942) as modified by Heermann and Hein (1968) (Method 1), rain gauges installed to represent a sampling area of 0.5 ha with CUC calculated according to Christiansen (1942) (Method 2), the methods 3, 4, 5, 6 and 7, were same as Method 2, but with collectors installed to represent sample area of $1,2,3,4$ or 5 ha, respectively. The area being adequately irrigated (ABAI) was calculated to obtain regression coefficient. The uniformity determined by method 2, most closely correlated with the concept of ABAI, followed by the methods 1 and 3 . The pivots in 40,60, 80, 100 and 120 ha size are recommended for testing uniformity with collectors representing sampling areas up to 1.0, 1.1, 1.3, 1.4 and 1.6 ha, respectively.

Keywords: area being adequately irrigated, uniformity coefficient, irrigation efficiency, sprinkle irrigation.

\footnotetext{
Recebido para publicação em 28/01/2011. Aprovado em 28/11/2011.

1- Engenheiro Agrônomo, Professor da UFMS/Chapadão do Sul-MS, fernando.cunha@ufms.br

2- Engenheiro Agrônomo, Professor do IFES/Santa Teresa-ES, ghsvieira@gmail.com

3- Engenheiro Agrícola, Professor do IFGO/Urutaí-GO, jarstec@yahoo.com.br

4- Engenheiro Agrícola, Professor da UFERSA/Mossoró-RN, eng.batista@gmail.com

5- Engenheiro Agrônomo, Professor do IFNMG/Salinas-MG, mrossivicente@gmail.com
} 


\section{INTRODUÇ̃̃O}

O aumento da produção na agricultura irrigada está diretamente relacionado com a utilização de sistemas de irrigação eficientes, que garantam um bom retorno do investimento aplicado pelo produtor, pois permite um melhor aproveitamento da água aplicada e maior número de colheitas em um determinado período (DANTAS NETO et al., 2009).

O Brasil possui uma área irrigada total de 4.453.910 ha, sendo que desses, 840.050 ha são com pivô central (PAULINO et al., 2011). Diversas vantagens são destacadas nouso desses equipamentos de irrigação e uma delas é a possibilidade da completa automação do sistema, conforme estudo de Peters e Evett (2008), que apresentam um sistema de automação acionado segundo a temperatura da superfície foliar das culturas.

Devido à tendência de decréscimo da disponibilidade de água para a agricultura e ao aumento dos custos de energia (LÓPEZ-MATA et al., 2010), é crescente a preocupação mundial com os recursos hídricos levando à adoção de estratégias de manejo que possibilitem economia de água sem prejuízos da produtividade das culturas. Uma boa estratégia de manejo da irrigação é fundamental para economizar água sem, no entanto, por em risco o rendimento das culturas (JALOTA et al., 2006; PEREIRA et al., 2009), devendo-se levar em consideração diversos fatores, além das interrelações clima-solo-água-planta.

Por irrigarem grandes áreas, os pivôs centrais consomem um volume grande de água e, diante disso, a utilização de equipamentos mais eficientes é uma busca constante. Entretanto, por melhor que seja o equipamento, a distribuição da água aplicada jamais será plenamente uniforme e a mensuração dessa variabilidade é fundamental na avaliação do desempenho da irrigação (SILVA et al., 2004). De acordo com Heinemann et al. (1998), os fatores que afetam a uniformidade de distribuição da água são os climáticos, como a evaporação, temperatura do ar, umidade relativa e condições locais do vento e os fatores não climáticos, que são os relacionados ao equipamento de irrigação, como a pressão de operação do emissor, velocidade e alinhamento das torres e altura do emissor.

A avaliação da uniformidade de distribuição de água em pivôs centrais deve ser feita ao longo da linha lateral, consistindo na coleta das precipitações por meio de coletores (pluviômetros) instalados ao longo de uma linha radial, partindo do ponto central do pivô, numerados em ordem crescente e espaçados, um do outro, entre 4 e $6 \mathrm{~m}$ (BERNARDO et al., 2008). Esses dados depois de coletados serão inseridos em equações para estimativa da uniformidade. Muitos coeficientes são usados para expressar a variabilidade de distribuição da água aplicada por um sistema de irrigação, sendo o mais utilizado para sistemas por aspersão, o proposto por Christiansen (1942), mais conhecido como Coeficiente de Uniformidade de Christiansen (CUC).

Keller e Bliesner (1990) relatam que além do CUC, deve-seutilizartambéma área adequadamente irrigada (AAI), que representa a porcentagem da área que durante uma irrigação, recebe uma lâmina igual ou superior à lâmina real necessária. A eficiência de irrigação para área adequadamente irrigada é um parâmetro que combina os valores obtidos para uniformidade de distribuição de água, a adequação da irrigação e as perdas que normalmente ocorrem no sistema. Assim, a eficiência de irrigação para área adequadamente irrigada congrega os efeitos devidos às perdas por desuniformidade de distribuição, perdas por percolação, perdas por evaporação e deriva e as perdas na condução.

$\mathrm{Na}$ equação desenvolvida por Christiansen (1942) está intrínseco que cada coletor representa áreas de mesmo tamanho, uma vez que foi desenvolvido para sistemas de aspersão convencional. Isto não ocorre em pivô central, em que os coletores são equidistantemente espaçados ao longo de uma linha radial, que parte do ponto central do pivô até à sua extremidade. Dessa forma, Heermann e Hein (1968) redefiniram o CUC, para sistemas do tipo pivô central, ponderando as lâminas coletadas em relação à posição do coletor, a partir do ponto central do pivô. No entanto, essa metodologia é falha, não devido à ponderação, mas na disposição dos coletores no campo. Os coletores próximos à extremidade do pivô terão uma área amostral muito grande, e mesmo que a ponderação corrija essa influência, esse coletor não representará a aplicação da irrigação de forma 
fiel. Considerando a locação de um coletor abaixo de um emissor entupido próximo à extremidade do pivô, sabendo que em sua volta todos estão funcionando corretamente, esse dado coletado não representa a real condição, devido ao fator de ordem ser grande, contribuindo significativamente para a subestimativa do CUC. Diante disso, o mais pertinente seria a instalação de um maior número de coletores na extremidade desse pivô, de forma a representar uma condição mais fiel da uniformidade de distribuição da irrigação por esse equipamento.

Diante do exposto, objetivou-se com este trabalho, propor uma nova metodologia para determinar a uniformidade de distribuição de água por pivôs centrais.

\section{MATERIAL E MÉTODOS}

Foram avaliados pivôs centrais equipados com emissores convencionais com área irrigada de 40, 60, 80, 100 e 120 ha. Para cada tamanho de pivô, foram avaliados dez sistemas diferentes nos municípios de Paracatu/MG, Barreiras/BA e Luís Eduardo Magalhães/BA, totalizando 50 pivôs avaliados.

Os pivôs centrais de Paracatu estavam ocupados com as culturas milho, feijão e canade-açúcar e os sistemas instalados em Barreiras e Luís Eduardo Magalhães com café. Os pivôs apresentavam-se com diferentes idades e estados de conservação, intensidades de aplicação de água, pressões de serviço e espaçamento entre emissores. As avaliações foram realizadas com seus percentímetros regulados a $100 \%$ de velocidade.

Os pivôs centrais foram avaliados por diferentes metodologias para cálculo e obtenção dos dados para determinação de suas uniformidades de distribuição de água, sendo definidas como:

- Método 1: com pluviômetros espaçados de 3 $m$ entre si e com o coeficiente de uniformidade de Christiansen (CUC) calculado conforme Christiansen (1942), modificado por Heermann e Hein (1968);

- Método 2: pluviômetros instalados de forma que cada um representasse uma área amostral de 0,5 hectare, com o CUC calculado conforme
Christiansen (1942); e

- Métodos 3, 4, 5, 6 e 7: idem ao método 2, porém com coletores instalados de forma que cada um representasse área amostral de 1, 2, 3, 4 e 5 hectares, respectivamente.

Para se determinar a uniformidade de distribuição do sistema pivô central, foi utilizado pluviômetros, hastes e proveta graduada. Instalaram-se coletores (pluviômetros) numerados, em ordem crescente, a partir do ponto central do pivô. Foram instaladas duas fileiras de coletores, do centro até a extremidade da área irrigada, formando um ângulo de $3^{\circ}$ entre si, sendo que na mesma malha de coletores, os pluviômetros ficaram distanciados de três metros entre si. No método 1 , a medida que se afasta do centro do pivô, há a necessidade de ponderar os valores de precipitação coletada, uma vez que cada coletor representa uma área amostral diferente. $\mathrm{O}$ fator de ponderação é o número de ordem do coletor, isto é, o volume ponderado equivale ao produto do volume coletado pelo número de ordem do coletor. Procedeu-se o cálculo da uniformidade de distribuição da irrigação por meio da equação 1, conforme Christiansen (1942), modificado por Heermann e Hein (1968).

$$
C U C=100\left[1-\frac{\sum_{i=1}^{n} S_{i}\left|X_{i}-\bar{X}\right|}{\bar{X} \sum_{i=1}^{n} S_{i}}\right]
$$

em que

CUC $=$ coeficiente de uniformidade de Christiansen (\%); $\mathrm{n}=$ número de coletores;

$\mathrm{S}_{\mathrm{i}}=$ distância do ponto central do pivô ao ponto i, ou número do coletor;

$\mathrm{Xi}=$ precipitação observada no coletor i $(\mathrm{mm})$; e

$\mathrm{X}=$ lâmina média ponderada das precipitações $(\mathrm{mm})$.

A ponderação feita nos cálculos de uniformidade do método 1 , foi realizada no próprio campo para os demais métodos, ou seja, ao invés de aumentar o número de ordem, aumentou-se o número de pluviômetros conforme distanciava-se do ponto 
central do pivô. No método 2 os espaçamentos entre os pluviômetros foram diminuindo conforme distanciava do ponto central do pivô, de forma que cada pluviômetro instalado no campo representasse uma área de 0,5 ha. Assim, utilizando a equação da área do círculo, foi possível determinar o raio, correspondente à distância entre o ponto central do pivô e o limite da área representada pelo pluviômetro. O resultado desse cálculo foi de $40 \mathrm{~m}$, e assim, o primeiro pluviômetro foi instalado na metade dessa distância, ou seja, a 20 metros do ponto central do pivô (Figura 1).

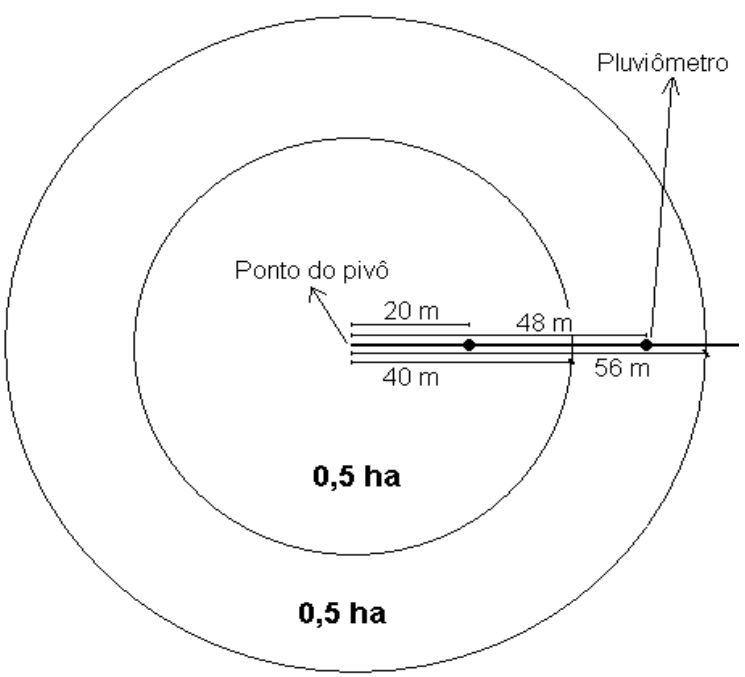

Figura 1. Instalação dos pluviômetros na avaliação da uniformidade em pivô central.

Para a determinação do ponto referente à instalação do segundo pluviômetro, que também representou uma área de 0,5 ha, foi realizado cálculo semelhante, mas considerando área de $10.000 \mathrm{~m}^{2}$ (1 ha), resultando num valor de " $R$ " de 56 metros. Descontando os primeiros 40 metros, referentes à área do primeiro coletor, restaram 16 metros. Diante disso, o segundo coletor foi instalado a uma distância de 8 metros, contados a partir do limite da área referente ao primeiro coletor, ou a 48 metros de distância do ponto central do pivô (Figura 1). Para os demais coletores, procederam-se os mesmos cálculos.

O princípio da metodologia e de cálculos foi baseado no exposto anteriormente, entretanto, uma outra equação, mais complexa, porém de uso mais simples, foi desenvolvida para obtenção do ponto em que cada coletor seria instalado em função de seu número de ordem e da área que representaria na avaliação.

Para encontrar a posição do pluviômetro “i” (Figura 2), ou a distância entre o ponto central do pivô e o pluviômetro "i", utilizou-se a equação 2 :

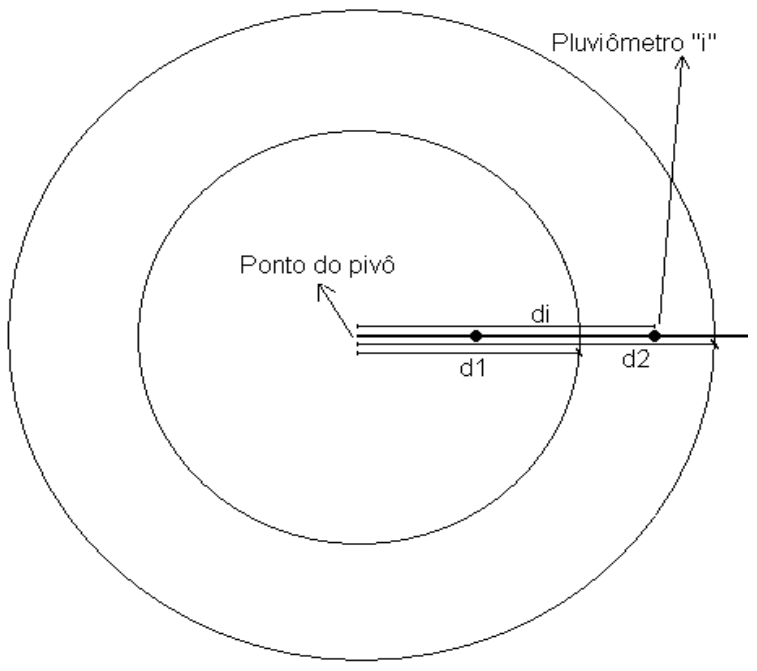

Figura 2. Instalação dos pluviômetros na avaliação da uniformidade em pivô central.

$d_{i}=\frac{d_{2}-d_{1}}{2}+d_{1}$

em que

$\mathrm{d}_{\mathrm{i}}=$ distância entre o ponto central do pivô e o coletor "i" ( $\mathrm{m})$;

$\mathrm{d}_{2}=$ distância entre o ponto central do pivô e o limite da área representada pelo coletor "i" (m); e $\mathrm{d}_{1}=$ distância entre o ponto central do pivô e o limite da área representada pelo coletor "i-1" (m).

Para obtenção de $\mathrm{d}_{1}$ ou d $\mathrm{d}_{2}$ utiliza-se a equação 3 :

$d_{1 \text { ои } 2}=\frac{\left[\frac{N_{i} \times A \times 40.000}{\pi}\right]^{\frac{1}{2}}}{2}$

em que

$\mathrm{N}_{\mathrm{i}}=$ número de ordem do coletor "i"; $\mathrm{e}$

$\mathrm{A}$ = área que o coletor irá representar na avaliação

\section{REVENG}

151-162 p. ENGENHARIA NA AGRICULTURA, VIÇOSA - MG, V.20 N.2, MARÇO / ABRIL 2012 
da uniformidade (ha).

Substituindo a equação 3 em 2, têm-se:

$$
d_{i}=\frac{\frac{\left[\frac{N_{i} \times A \times 40.000}{\pi}\right]^{\frac{1}{2}}}{2}-\frac{\left[\frac{\left(N_{i}-1\right) \times A \times 40.000}{\pi}\right]^{\frac{1}{2}}}{2}}{\frac{\left[\frac{\left(N_{i}-1\right) \times A \times 40.000}{\pi}\right]^{\frac{1}{2}}}{2}}+
$$

Simplificando a equação 4, têm-se:

$\mathrm{d}_{\mathrm{i}}=50 \times\left(\frac{\mathrm{A}}{\pi}\right)^{\frac{1}{2}} \times\left[\mathrm{N}_{\mathrm{i}}^{\frac{1}{2}}+\left(\mathrm{N}_{\mathrm{i}}-1\right)^{\frac{1}{2}}\right]$

em que

$d_{i}=$ distância entre o ponto central do pivô e o coletor "i" (m);

$\mathrm{A}$ = área que o coletor irá representar na avaliação da uniformidade (ha); e

$\mathrm{N}_{\mathrm{i}}=$ número de ordem do coletor "i”".

Diante da Equação 5, obteve-se todas as posições dos coletores para as demais metodologias propostas na presente pesquisa. No Quadro 1 está apresentado o número de coletores utilizados para cada metodologia e tamanho de pivô central.

Diante dos resultados de precipitação coletados nos pluviômetros instalados de acordo com a Equação 5, procedeu-se aos cálculos da uniformidade de distribuição de água conforme a equação de Christiansen (1942):

$$
C U C=100\left[1-\frac{\sum_{i=1}^{n}\left|X_{i}-\bar{X}\right|}{n \bar{X}}\right]
$$

em que

$\mathrm{CUC}=$ coeficiente de uniformidade de Christiansen $(\%)$;

$\underline{\mathrm{X}}=$ precipitação observada nos coletores $(\mathrm{mm})$;

$X=$ média das precipitações (mm); e

$\mathrm{n}=$ número de coletores.

A obtenção da área adequadamente irrigada (AAI) em cada avaliação foi obtida de acordo com a porcentagem da área que recebeu uma lâmina d'água igual ou superior à lâmina real necessária (KELLER; BLIESNER, 1990). Observa-se, na Figura 3, que no eixo das abscissas estão os valores de área acumulada e nas ordenadas a relação entre a lâmina coletada e a lâmina média. Quanto menor for a uniformidade de distribuição de água, maior será a inclinação da reta ajustada, pois maior quantidade de área à esquerda da figura receberá maior lâmina de irrigação e maior quantidade de área à direita da figura receberá menor lâmina de irrigação. $\mathrm{O}$ aumento na inclinação da reta resulta em um maior coeficiente de regressão da reta $\left(\beta_{1}\right)$, em módulo. Diante disso, a equação que melhor

Quadro 1. Quantidade de coletores utilizados no campo para determinação da uniformidade de distribuição de água conforme metodologia utilizada e tamanho de pivô central

\begin{tabular}{ccccccccc}
\hline Pivô & \multicolumn{8}{c}{ Metodologia } \\
\hline $\begin{array}{c}\text { Tamanho } \\
\text { (hectares) }\end{array}$ & $\begin{array}{c}\text { Raio } \\
\text { (metros) }\end{array}$ & $(1)^{*}$ & $(2)^{*}$ & $(3)^{*}$ & $(4)^{*}$ & $(5)^{*}$ & $(6)^{*}$ & $(7)^{*}$ \\
\hline 40 & 357 & 119 & 80 & 40 & 20 & 13 & 10 & 8 \\
60 & 437 & 146 & 120 & 60 & 30 & 20 & 15 & 12 \\
80 & 505 & 168 & 160 & 80 & 40 & 27 & 20 & 16 \\
100 & 564 & 188 & 200 & 100 & 50 & 33 & 25 & 20 \\
120 & 618 & 206 & 240 & 120 & 60 & 40 & 30 & 24 \\
\hline
\end{tabular}

*Método 1: coeficiente de uniformidade (CUC) calculado conforme Christiansen (1942), modificado por Heermann e Hein (1968); Método 2: pluviômetros instalados de forma que cada um representasse uma área amostral de 0,5 ha com o CUC calculado conforme Christiansen (1942); Métodos 3, 4, 5, 6 e 7: idem método 2, porém com coletores instalados de forma que cada um representasse área amostral de 1, 2, 3, 4 e 5 ha. 
representa a uniformidade de distribuição de água de um sistema de irrigação será aquela que obtiver a melhor relação entre aumento no coeficiente de regressão, em módulo, dado pelo gráfico da AAI, e redução do coeficiente de uniformidade de distribuição de água.

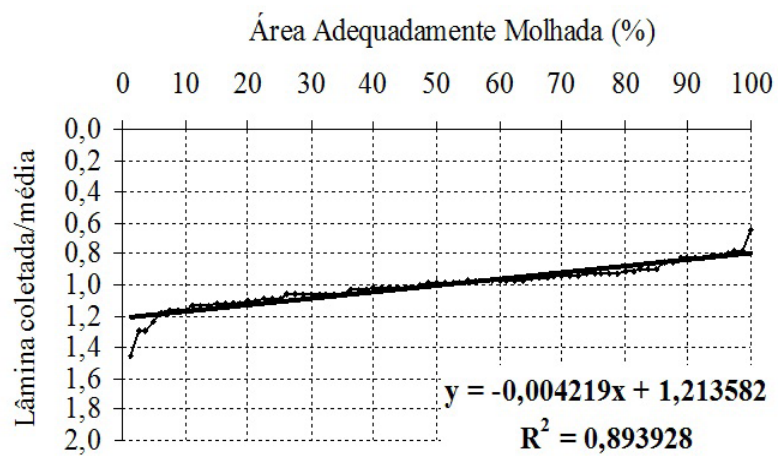

Figura 3. Relação da lâmina coletada e média, e ordenada de forma decrescente, em função da fração acumulada de área irrigada.

Em cada teste para avaliação da uniformidade de distribuição de água, foi obtido o valor de uniformidade pelas 7 metodologias e o gráfico da AAI. De posse do gráfico de dispersão da AAI, foi ajustada uma regressão linear de primeiro grau. Após a obtenção dessas informações, plotou-se na abscissa os valores do coeficiente de regressão $\beta_{1}$ e nas ordenadas os valores de uniformidade. Esses dados foram submetidos às análises de regressão. A escolha da metodologia que melhor combina o valor da uniformidade de distribuição de água com a AAI foi baseada na significância dos coeficientes de regressão, utilizando-se o teste $t$ e no coeficiente de determinação $\left(r^{2}\right)$. Para comparar as uniformidades de distribuição de água dentro de cada teste, considerou-se o coeficiente de uniformidade de Christiansen (CUC), modificado por Heermann e Hein (1968) como o padrão, não permitindo um desvio médio da diferença maior que dois para validar a metodologia.

\section{RESULTADOS E DISCUSSÃO}

Observa-se na Figura 4 e Quadro 2, que todos os modelos ajustados tiveram seus coeficientes de regressão significativos à $0,1 \%$ de probabilidade, corroborando com os resultados obtidos por Cunha et al. (2009) para pivôs centrais com emissores convencionais utilizando a metodologia de Christiansen (1942) modificado por Heermann e Hein (1968). Observa-se também na Figura 4 que as metodologias para cálculo da uniformidade de pivô central usando pluviômetros espaçados de $3 \mathrm{~m}$ entre si e com o coeficiente de uniformidade de Christiansen (CUC) calculado conforme Christiansen (1942) modificado por Heermann e Hein (1968) (Método 1), e as metodologias utilizando pluviômetros instalados de forma que cada um representasse uma área amostral de 0,5 (Método 2) e 1,0 hectare (Método 3), com o CUC calculado conforme Christiansen (1942), apresentaram coeficientes de determinação $\left(r^{2}\right)$ superiores a $90 \%$, mostrando que a redução da uniformidade proporciona aumento do coeficiente de regressão, em módulo, retirado do gráfico da área adequadamente irrigada (AAI). Baseado nos valores de $\mathrm{r}^{2}$, os métodos que apresentaram melhor relação entre a uniformidade de distribuição de água e o coeficiente de regressão retirado do gráfico da $\mathrm{AAI}$, em ordem decrescente para pivôs centrais de 40 hectares foram: Métodos 2, 1, 3, 7, 6, 5 e 4.

Para pivôs centrais de 80 hectares e para metodologia 6 - pluviômetros instalados de forma que cada um representasse uma área amostral de 4,0 hectares com o CUC calculado conforme Christiansen (1942), observa-se que o $\mathrm{r}^{2}$ foi inferior a $90 \%$, mostrando que com a redução da uniformidade, houve menor precisão do coeficiente de regressão retirado do gráfico da AAI (Quadro 2). Os demais tratamentos apresentaram $r^{2}$ superiores a 90\%, sendo que o método 2 sempre apresentou melhor uniformidade de distribuição de água relacionado ao coeficiente de regressão retirado do gráfico da AAI, seguido dos métodos 1 e 3 .

É bom salientar que a coleta da irrigação foi realizada com coletores sobre o solo, e de acordo com resultados obtidos por Saad e Libardi (1994) em pivô central cultivado com feijão, há uma redistribuição da água quando a água infiltra no perfil do solo, tornando a irrigação mais uniforme. Cainelli et al. (1998) trabalhando com pivô central em Fortaleza dos Vales/ RS, também verificaram maiores uniformidades no sub-solo, além disso, os autores verificaram que a uniformidade aumentava conforme aumentava-se a profundidade avaliada e o tempo após a aplicação da irrigação. Diante disso, espera-se que a utilização da metodologia avaliando a lâmina de água no solo em substituição da metodologia convencional, coletando sob o solo, maiores coeficientes de determinação serão obtidos para a uniformidade de distribuição de água em função dos coeficientes de regressão retirados do gráfico da AAI. 

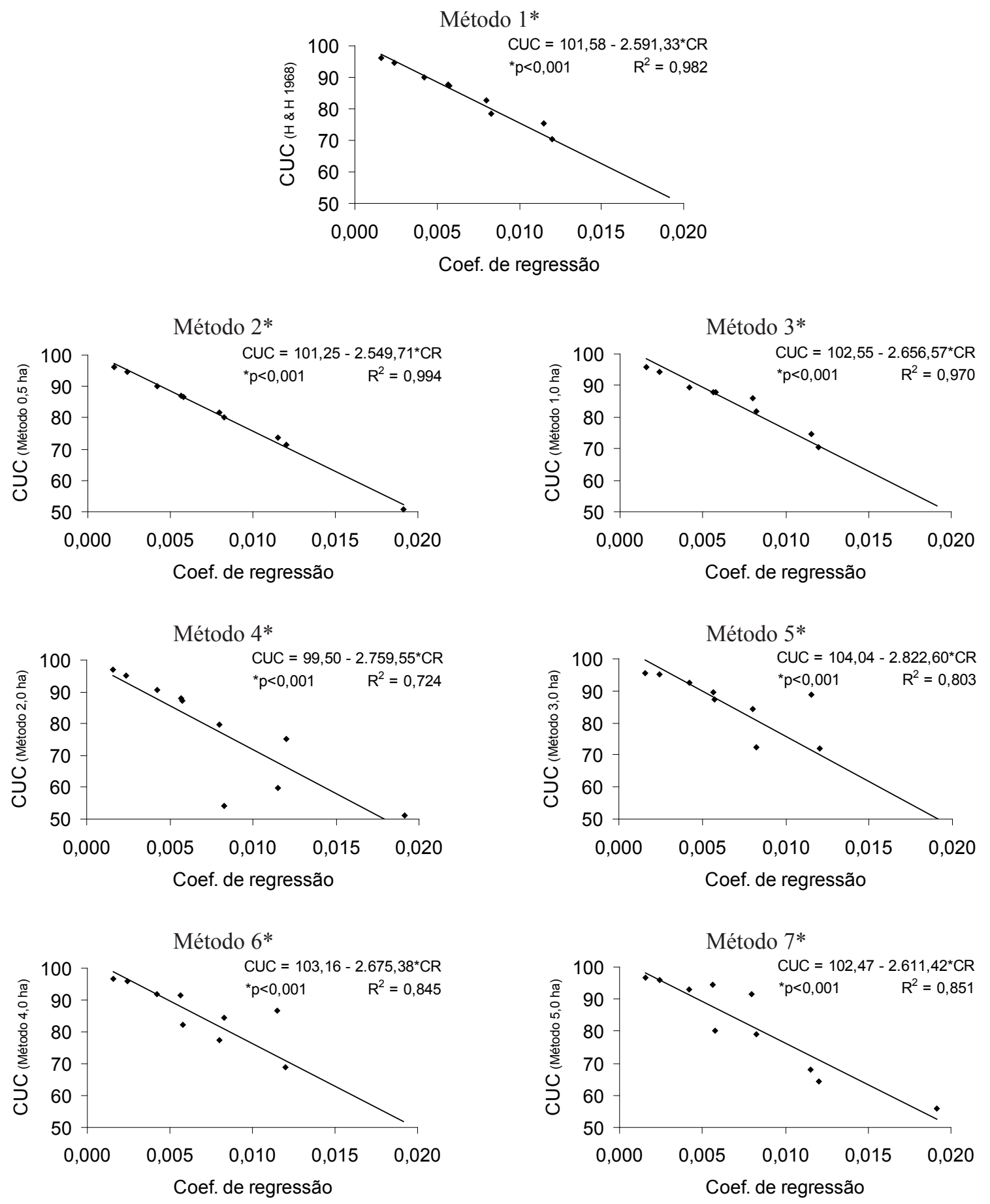

*Método 1: coeficiente de uniformidade (CUC) calculado conforme Christiansen (1942), modificado por Heermann e Hein (1968); Método 2: pluviômetros instalados de forma que cada um representasse uma área amostral de 0,5 ha com o CUC calculado conforme Christiansen (1942); Métodos 3, 4, 5, 6 e 7: idem método 2, porém com coletores instalados de forma que cada um representasse área amostral de 1, 2, 3, 4 e 5 ha

Figura 4. Regressões e coeficientes de determinação $\left(\mathrm{r}^{2}\right)$ de coeficientes de uniformidade de Christiansen (CUC em \%) em função dos coeficientes de regressão retirados do gráfico da AAI, em módulo (em decimal), para diferentes métodos de avaliação de um pivô central de 40 ha. 
Quadro 2. Regressões e coeficientes de determinação $\left(\mathrm{r}^{2}\right)$ de coeficientes de uniformidade de Christiansen (CUC em \%) em função dos coeficientes de regressão (CR) retirados do gráfico da AAI, em módulo (em decimal), para diferentes métodos de avaliação e tamanhos de pivô central

\begin{tabular}{|c|c|c|c|}
\hline Pivô & Método & Regressão & $\mathrm{r}^{2}$ \\
\hline \multirow{7}{*}{60 ha } & Método $1 * *$ & $\mathrm{CUC}=101,75-2.609,32 * \mathrm{CR}$ & 0,991 \\
\hline & Método $2 * *$ & $\mathrm{CUC}=101,68-2.631,16^{*} \mathrm{CR}$ & 0,996 \\
\hline & Método $3 * *$ & $\mathrm{CUC}=102,17-2.638,75^{*} \mathrm{CR}$ & 0,983 \\
\hline & Método $4 * *$ & $\mathrm{CUC}=101,65-2.312,39 * \mathrm{CR}$ & 0,936 \\
\hline & Método $5 * *$ & $\mathrm{CUC}=100,63-2.480,26^{*} \mathrm{CR}$ & 0,955 \\
\hline & Método $6 * *$ & $\mathrm{CUC}=101,24-2.576,70^{*} \mathrm{CR}$ & 0,972 \\
\hline & Método $7 * *$ & $\mathrm{CUC}=100,41-2.543,99 * \mathrm{CR}$ & 0,966 \\
\hline \multirow{7}{*}{80 ha } & Método $1 * *$ & $\mathrm{CUC}=100,73-2.441,35^{*} \mathrm{CR}$ & 0,998 \\
\hline & Método $2 * *$ & $\mathrm{CUC}=100,58-2.443,65^{*} \mathrm{CR}$ & 0,999 \\
\hline & Método $3 * *$ & $\mathrm{CUC}=101,71-2.556,97^{*} \mathrm{CR}$ & 0,991 \\
\hline & Método $4 * *$ & $\mathrm{CUC}=99,67-2.355,76^{*} \mathrm{CR}$ & 0,961 \\
\hline & Método $5 * *$ & $\mathrm{CUC}=102,14-2.481,55^{*} \mathrm{CR}$ & 0,954 \\
\hline & Método $6 * *$ & $\mathrm{CUC}=100,39-2.418,28 * \mathrm{CR}$ & 0,857 \\
\hline & Método $7 * *$ & $\mathrm{CUC}=102,79-2.857,83^{*} \mathrm{CR}$ & 0,965 \\
\hline \multirow{7}{*}{100 ha } & Método $1 * *$ & $\mathrm{CUC}=100,96-2.533,79 * \mathrm{CR}$ & 0,990 \\
\hline & Método $2 * *$ & $\mathrm{CUC}=101,27-2.559,48^{*} \mathrm{CR}$ & 0,991 \\
\hline & Método $3 * *$ & $\mathrm{CUC}=100,88-2.506,50 * \mathrm{CR}$ & 0,986 \\
\hline & Método $4 * *$ & $\mathrm{CUC}=98,89-2.165,25^{*} \mathrm{CR}$ & 0,963 \\
\hline & Método $5 * *$ & $\mathrm{CUC}=99,98-2.403,13 * \mathrm{CR}$ & 0,978 \\
\hline & Método $6 * *$ & $\mathrm{CUC}=103,48-2.784,67^{*} \mathrm{CR}$ & 0,967 \\
\hline & Método $7 * *$ & $\mathrm{CUC}=100,81-2.569,19 * \mathrm{CR}$ & 0,966 \\
\hline \multirow{7}{*}{120 ha } & Método $1 * *$ & $\mathrm{CUC}=101,08-2.560,12 * \mathrm{CR}$ & 0,972 \\
\hline & Método $2 * *$ & $\mathrm{CUC}=100,67-2.496,94 * \mathrm{CR}$ & 0,973 \\
\hline & Método $3 * *$ & $\mathrm{CUC}=100,97-2.538,09 * \mathrm{CR}$ & 0,968 \\
\hline & Método $4 * *$ & $\mathrm{CUC}=99,34-2.396,32 * \mathrm{CR}$ & 0,949 \\
\hline & Método $5 * *$ & $\mathrm{CUC}=100,93-2.378,05^{*} \mathrm{CR}$ & 0,950 \\
\hline & Método $6^{* *}$ & $\mathrm{CUC}=101,29-2.435,91 * \mathrm{CR}$ & 0,939 \\
\hline & Método $7 * *$ & $\mathrm{CUC}=102,27-2.612,85^{*} \mathrm{CR}$ & 0,947 \\
\hline
\end{tabular}

${ }^{*} p<0,001$. **Método 1: coeficiente de uniformidade (CUC) calculado conforme Christiansen (1942), modificado por Heermann e Hein (1968); Método 2: pluviômetros instalados de forma que cada um representasse uma área amostral de 0,5 ha com o CUC calculado conforme Christiansen (1942); Métodos 3, 4, 5, 6 e 7: idem método 2, porém com coletores instalados de forma que cada um representasse área amostral de 1, 2, 3, 4 e 5 ha.

No Quadro 3 está apresentada a comparação entre os valores de uniformidade de distribuição de água para diferentes metodologias de avaliação, equipamentos e tamanhos de pivô central equipado com emissores convencionais. Para os pivôs de 40 hectares, observou-se que as metodologias utilizando área amostral de 0,5 e 1,0 hectare não diferiram mais que $2 \%$ dos valores obtidos pela metodologia 1 - Christiansen (1942), modificado por Heermann e Hein (1968). Verifica-se no Quadro 1, que no método 1 foi necessária a utilização de 119 coletores no campo, já no método 3 (área amostral de 1,0 hectare), foram necessários apenas 40 pluviômetros.
Diante disso, para avaliação de pivôs centrais de 40 hectares, poder-se-ia espalhar um número menor de coletores no campo, economizando equipamento e tempo na coleta dos dados. Utilizando área amostral de 0,5 hectare, a quantidade de coletores a serem instalados seria de 80, economizando também equipamento e tempo em relação à metodologia 1. Entretanto, utilizando a metodologia de área amostral de 0,5 hectare possibilitaria uma maior precisão no levantamento da uniformidade de distribuição da água pelo sistema, por essa metodologia estar mais relacionada ao coeficiente de regressão retirado do gráfico da $\mathrm{AAI}$.

\section{REVENG}

151-162 p. ENGENHARIA NA AGRICULTURA, VIÇOSA - MG, V.20 N.2, MARÇO / ABRIL 2012 
Quadro 3. Valores de uniformidade de distribuição de água calculado por diferentes métodos e tamanhos de pivô central

\begin{tabular}{|c|c|c|c|c|c|c|c|c|}
\hline \multirow{2}{*}{$\begin{array}{c}\text { Pivô Central } \\
\text { Tamanho }\end{array}$} & \multirow[b]{2}{*}{ Teste } & \multicolumn{7}{|c|}{ Métodos } \\
\hline & & $1 *$ & $2 *$ & $3 *$ & $4 *$ & $5 *$ & $6^{*}$ & $7 *$ \\
\hline \multirow[t]{3}{*}{ 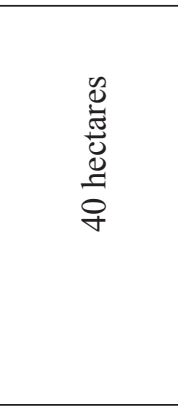 } & $\begin{array}{c}1 \\
2 \\
3 \\
4 \\
5 \\
6 \\
7 \\
8 \\
9 \\
9 \\
10 \\
\end{array}$ & $\begin{array}{l}94,7 \\
87,3 \\
75,5 \\
87,5 \\
70,5 \\
82,7 \\
78,5 \\
89,9 \\
96,0 \\
49,7 \\
\end{array}$ & $\begin{array}{l}94,6 \\
86,5 \\
73,7 \\
86,8 \\
71,3 \\
81,8 \\
80,3 \\
90,2 \\
96,1 \\
50,7 \\
\end{array}$ & $\begin{array}{l}94,4 \\
87,9 \\
74,6 \\
88,0 \\
70,5 \\
85,8 \\
82,0 \\
89,4 \\
95,9 \\
48,2 \\
\end{array}$ & $\begin{array}{l}95,0 \\
87,3 \\
59,9 \\
88,0 \\
75,4 \\
79,7 \\
54,1 \\
90,5 \\
97,0 \\
51,1 \\
\end{array}$ & $\begin{array}{l}95,1 \\
87,2 \\
88,8 \\
89,7 \\
72,0 \\
84,4 \\
72,4 \\
92,4 \\
95,6 \\
41,0 \\
\end{array}$ & $\begin{array}{l}95,9 \\
82,2 \\
86,7 \\
91,5 \\
68,8 \\
77,5 \\
84,6 \\
91,8 \\
96,5 \\
46,0 \\
\end{array}$ & $\begin{array}{l}96,0 \\
80,2 \\
68,2 \\
94,5 \\
64,4 \\
91,4 \\
79,0 \\
93,1 \\
96,7 \\
55,9 \\
\end{array}$ \\
\hline & Média dos desvios & & 1,11 & 1,45 & 6,78 & 5,33 & 5,31 & 6,39 \\
\hline & Desvio das médias & & 0,88 & 1,64 & 10,55 & 6,77 & 4,21 & 4,39 \\
\hline \multirow[t]{3}{*}{ 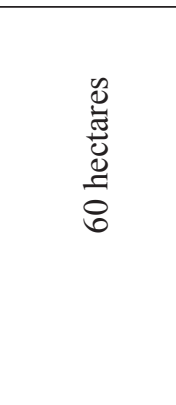 } & $\begin{array}{c}1 \\
2 \\
3 \\
4 \\
5 \\
6 \\
7 \\
8 \\
9 \\
10 \\
\end{array}$ & $\begin{array}{l}87,6 \\
93,0 \\
97,6 \\
56,2 \\
85,4 \\
88,1 \\
68,0 \\
59,1 \\
78,8 \\
43,6 \\
\end{array}$ & $\begin{array}{l}88,0 \\
93,2 \\
97,7 \\
55,1 \\
84,0 \\
88,5 \\
67,5 \\
58,5 \\
77,7 \\
44,2 \\
\end{array}$ & $\begin{array}{l}87,2 \\
93,1 \\
97,4 \\
57,2 \\
86,9 \\
87,8 \\
69,1 \\
57,3 \\
79,9 \\
42,6 \\
\end{array}$ & $\begin{array}{l}88,3 \\
91,6 \\
97,4 \\
64,3 \\
87,1 \\
89,6 \\
73,7 \\
66,0 \\
83,8 \\
43,9 \\
\end{array}$ & $\begin{array}{l}85,4 \\
92,8 \\
97,2 \\
58,5 \\
86,8 \\
91,5 \\
68,0 \\
64,6 \\
70,3 \\
43,9 \\
\end{array}$ & $\begin{array}{l}90,6 \\
92,1 \\
96,8 \\
53,3 \\
85,9 \\
88,4 \\
61,5 \\
57,3 \\
79,3 \\
50,3 \\
\end{array}$ & $\begin{array}{l}81,9 \\
90,9 \\
97,6 \\
54,4 \\
87,4 \\
91,5 \\
64,8 \\
53,3 \\
78,1 \\
50,4\end{array}$ \\
\hline & Média dos desvios & & 0,93 & 1,30 & 4,79 & 3,35 & 3,96 & 4,90 \\
\hline & Desvio das médias & & 0,64 & 0,98 & 5,16 & 3,84 & 4,88 & 4,69 \\
\hline \multirow[t]{3}{*}{ 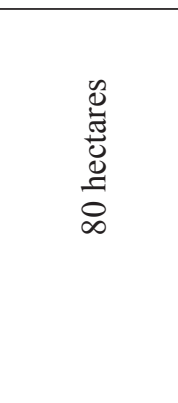 } & $\begin{array}{c}1 \\
2 \\
3 \\
4 \\
5 \\
6 \\
7 \\
8 \\
9 \\
10 \\
\end{array}$ & $\begin{array}{l}51,2 \\
81,5 \\
96,1 \\
88,7 \\
76,3 \\
70,0 \\
62,5 \\
95,9 \\
72,2 \\
83,5 \\
\end{array}$ & $\begin{array}{l}50,9 \\
80,7 \\
96,2 \\
88,0 \\
76,1 \\
70,5 \\
62,2 \\
96,0 \\
72,1 \\
83,4 \\
\end{array}$ & $\begin{array}{l}48,5 \\
81,4 \\
96,0 \\
88,8 \\
77,7 \\
71,2 \\
60,7 \\
96,2 \\
72,3 \\
84,0 \\
\end{array}$ & $\begin{array}{l}51,0 \\
72,9 \\
96,1 \\
89,2 \\
78,4 \\
69,6 \\
64,0 \\
95,2 \\
75,4 \\
83,5 \\
\end{array}$ & $\begin{array}{l}52,7 \\
87,9 \\
96,0 \\
90,0 \\
78,6 \\
73,0 \\
58,2 \\
96,4 \\
72,2 \\
83,1 \\
\end{array}$ & $\begin{array}{l}59,7 \\
88,7 \\
95,5 \\
91,6 \\
75,1 \\
68,3 \\
51,0 \\
94,5 \\
69,6 \\
82,4 \\
\end{array}$ & $\begin{array}{l}42,8 \\
76,8 \\
96,3 \\
90,3 \\
81,5 \\
65,0 \\
58,1 \\
94,9 \\
70,1 \\
83,4\end{array}$ \\
\hline & Média dos desvios & & 0,40 & 1,31 & 2,24 & 2,76 & 5,80 & 4,90 \\
\hline & Desvio das médias & & 0,35 & 1,64 & 3,25 & 2,80 & 6,59 & 4,96 \\
\hline \multirow[t]{3}{*}{ 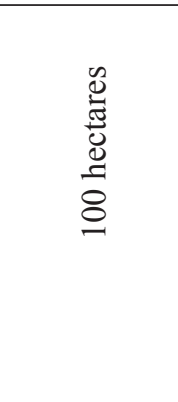 } & $\begin{array}{c}1 \\
2 \\
3 \\
4 \\
5 \\
6 \\
7 \\
8 \\
9 \\
10 \\
\end{array}$ & $\begin{array}{l}87,4 \\
93,9 \\
89,5 \\
95,4 \\
72,4 \\
66,6 \\
63,0 \\
58,4 \\
75,7 \\
45,6 \\
\end{array}$ & $\begin{array}{l}87,4 \\
94,1 \\
89,4 \\
95,5 \\
73,0 \\
67,3 \\
64,1 \\
58,0 \\
75,1 \\
44,5 \\
\end{array}$ & $\begin{array}{l}86,7 \\
94,0 \\
89,2 \\
95,4 \\
72,2 \\
69,2 \\
64,3 \\
56,5 \\
76,4 \\
46,0 \\
\end{array}$ & $\begin{array}{l}87,9 \\
93,2 \\
89,8 \\
95,3 \\
70,1 \\
68,3 \\
64,5 \\
66,4 \\
77,3 \\
52,4 \\
\end{array}$ & $\begin{array}{l}84,8 \\
94,2 \\
88,5 \\
95,5 \\
75,3 \\
70,6 \\
66,3 \\
58,1 \\
71,9 \\
46,5 \\
\end{array}$ & $\begin{array}{l}90,3 \\
93,2 \\
91,0 \\
95,9 \\
73,5 \\
62,2 \\
64,1 \\
61,5 \\
77,2 \\
38,2 \\
\end{array}$ & $\begin{array}{l}82,9 \\
92,7 \\
92,6 \\
95,8 \\
75,2 \\
67,3 \\
62,0 \\
53,6 \\
74,4 \\
46,2 \\
\end{array}$ \\
\hline & Média dos desvios & & 0,79 & 1,28 & 4,04 & 2,77 & 3,95 & 2,83 \\
\hline & Desvio das médias & & 0,77 & 1,38 & 5,50 & 2,19 & 4,73 & 2,41 \\
\hline \multirow[t]{3}{*}{ 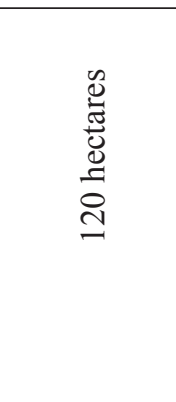 } & $\begin{array}{c}1 \\
2 \\
3 \\
4 \\
5 \\
6 \\
7 \\
7 \\
8 \\
9 \\
10 \\
\end{array}$ & $\begin{array}{l}52,6 \\
94,4 \\
89,4 \\
83,8 \\
94,0 \\
74,8 \\
72,3 \\
51,4 \\
64,8 \\
61,0 \\
\end{array}$ & $\begin{array}{l}53,9 \\
94,4 \\
89,3 \\
83,2 \\
94,1 \\
74,9 \\
72,9 \\
52,2 \\
64,6 \\
61,8 \\
\end{array}$ & $\begin{array}{l}51,4 \\
93,9 \\
89,0 \\
84,0 \\
94,0 \\
76,3 \\
72,2 \\
52,3 \\
62,9 \\
63,6 \\
\end{array}$ & $\begin{array}{l}53,6 \\
94,2 \\
89,5 \\
77,1 \\
94,0 \\
76,6 \\
70,9 \\
52,4 \\
67,9 \\
62,4 \\
\end{array}$ & $\begin{array}{l}54,9 \\
93,8 \\
88,6 \\
87,5 \\
94,1 \\
77,8 \\
74,7 \\
53,4 \\
66,3 \\
65,4 \\
\end{array}$ & $\begin{array}{l}60,3 \\
94,6 \\
91,3 \\
87,7 \\
94,3 \\
74,4 \\
73,2 \\
52,4 \\
64,9 \\
60,7 \\
\end{array}$ & $\begin{array}{l}51,1 \\
93,5 \\
92,7 \\
80,9 \\
94,1 \\
80,5 \\
75,5 \\
51,2 \\
65,3 \\
59,9 \\
\end{array}$ \\
\hline & Média dos desvios & & 0,74 & 1,43 & 2,32 & 3,13 & 2,67 & 2,61 \\
\hline & Desvio das médias & & 0,79 & 1,38 & 2,43 & 2,13 & 4,41 & 2,32 \\
\hline
\end{tabular}

*Método 1: coeficiente de uniformidade (CUC) calculado conforme Christiansen (1942), modificado por Heermann e Hein (1968); Método 2: pluviômetros instalados de forma que cada um representasse uma área amostral de 0,5 ha com o CUC calculado conforme Christiansen (1942); Métodos 3, 4, 5, 6 e 7: idem método 2, porém com coletores instalados de forma que cada um representasse área amostral de 1, 2, 3, 4 e 5 ha. 
Para os demais tamanhos de pivô, observou-se o mesmo em relação ao pivô de 40 hectares, em que as metodologias utilizando coletores representando área amostral de 0,5 e 1,0 hectare não diferiram da metodologia de ponderação proposta por Christiansen (1942), modificado por Heermann e Hein (1968). Verifica-se também que as metodologias que utilizam áreas amostrais superiores a 1,0 hectare apresentam valores com maior discrepância em relação à metodologia 1, quando utiliza-se pivôs com menor uniformidade. Trabalhando com pivôs centrais mais novos, com idade inferior a três anos, espera-se maior uniformidade, como relata Costa et al. (2005), e possivelmente, áreas amostrais maiores poderão ser utilizadas sem prejuízo na estimativa de sua uniformidade. Esse resultado corrobora com Davis (1966), que relata que quanto menor a uniformidade de um sistema de irrigação, maior o número de amostras serão necessárias para obtenção de um valor preciso.

Diante dos resultados encontrados, pode-se observar no Quadro 1 que a avaliação da uniformidade de pivôs centrais pode ser realizada com a disposição de menor número de coletores no campo. Entretanto, existiria um maior esforço para locar esses coletores no campo, visto que o espaçamento entre um e outro coletor seria reduzido conforme aproximasse da última torre do pivô. Outra desvantagem dos métodos 2 e 3 em relação ao método 1 seria o não levantamento da informação sobre mapeamento de bocal ao longo do pivô, para identificação da existência de diferentes emissores no caso de redimensionamento de sistemas.

Na Figura 5 estão apresentados os desvios-padrão (Quadro 3) em função das metodologias que utiliza coletores representando diferentes áreas amostrais, para cada tamanho de área. Verifica-se que as regressões ajustadas foram todas de segundo grau.
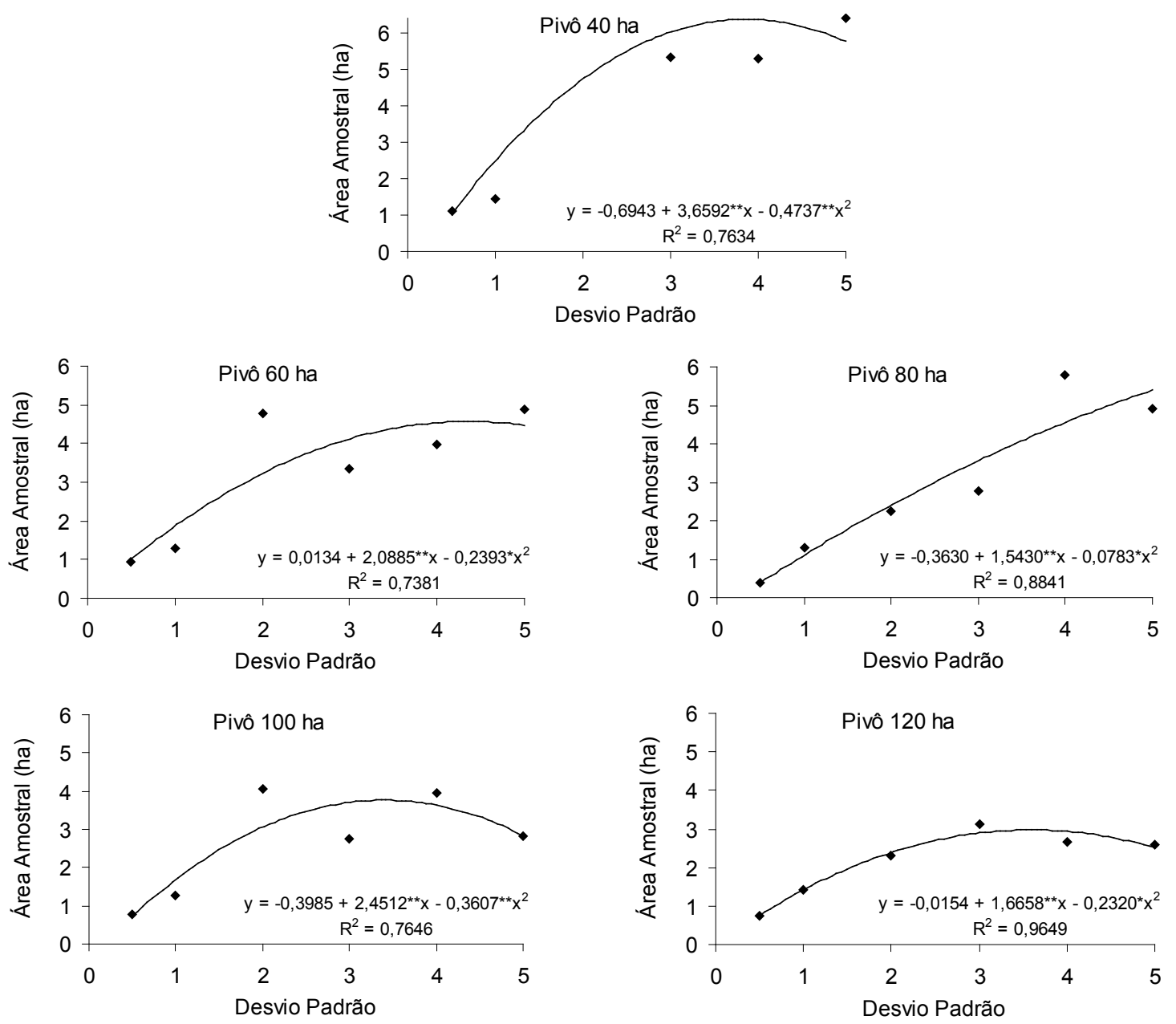

$* p<0,01$ e $* * p<0,001$

Figura 5. Valores de área amostral representada pelos coletores em função dos desvios-padrão para diferentes tamanhos de pivô central. 
Na Figura 6 ajustou-se uma regressão das áreas amostrais equivalentes aos desvios-padrão igual a dois em função dos diferentes tamanhos de pivô central. Com a equação, verificou-se que as áreas amostrais máximas para serem representadas por cada coletor no teste de uniformidade foi de 1,0 ; 1,$1 ; 1,3 ; 1,4$ e 1,6 hectares para tamanhos de pivô de $40,60,80,100$ e 120 hectares, respectivamente. Entretanto, cabe salientar que esses valores ainda podem ser modificados em função dos diferentes estados de conservação dos pivôs centrais e condições climáticas no momento da avaliação.

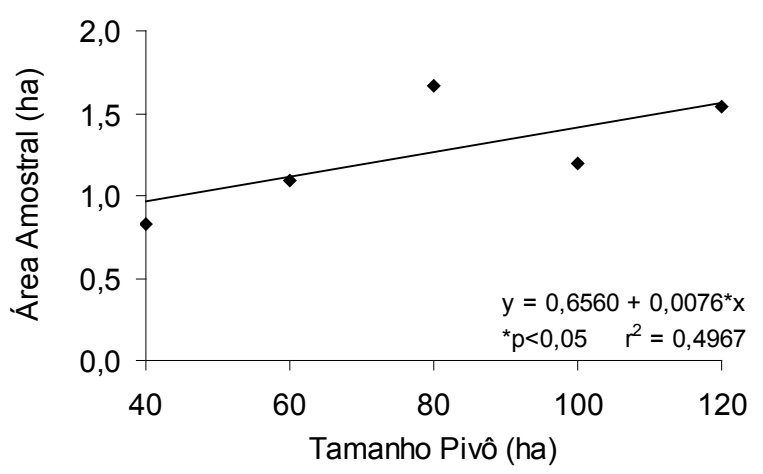

Figura 6. Área máxima permitida que deverá representar o coletor no teste de uniformidade para diferentes tamanhos de pivô central.

\section{CONCLUSÕES}

- A determinação da uniformidade de pivôs centrais utilizando pluviômetros instalados de forma que cada um represente uma área amostral de 0,5 hectare com o CUC calculado, conforme Christiansen (1942) é a metodologia mais indicada, por estar mais relacionada ao conceito de área adequadamente irrigada, seguida da metodologia de Christiansen (1942), modificado por Heermann e Hein (1968) e da metodologia utilizando coletores representando área amostral de 1,0 hectare; e

- Para pivôs centrais de tamanhos de 40, 60, 80, 100 e 120 hectares, recomendam-se testes de uniformidade com coletores representando áreas amostrais máximas até 1,$0 ; 1,1 ; 1,3 ; 1,4$ e 1,6 hectares, respectivamente.

\section{REFERÊNCIAS BIBLIOGRÁFICAS}

BERNARDO, S.; SOARES, A.A.; MANTOVANI, E.C. Manual de Irrigação. 8.ed. Viçosa: UFV, 2008. 625p.

CAINELLI, V.H.; ROBAINA, A.D.; CARLESSO, R.; DOTTO, C.R.D. Desempenho e uniformidade da distribuição de água de um pivô central. Ciência Rural, Santa Maria, v.27, n.4, p.35-40, Jan./Mar., 1998.

CHRISTIANSEN, J.E. Irrigation by Sprinkling. Berkeley: California Agricultural Station, 1942. 124p. Bulletin, 670 .

COSTA, M.B.; SILVA, J.G.F.; ESPINDULA NETO, D.; BOTREL, T.A. Uniformidade de aplicação de água e análise das irrigações por pivô central na fruticultura do mamão no município de Pinheiros, ES. In: SIMPÓSIO DO PAPAYA BRASILEIRO, 2, 2005, Vitória. Anais... Vitória: Gráfica Lisboa, 2005. p.394-396.

CUNHA, F.F.; ALENCAR, C.A.B.; VICENTE, M.R.; BATISTA, R.O.; SOUZA, J.A.R. Comparação de equações para cálculo da uniformidade de aplicação de água para diferentes sistemas de irrigação. Engenharia na Agricultura, Viçosa, v.17, n.5, p.404-417, Set./Out., 2009.

DANTAS NETO, J.; SILVA, J.C.S.; FARIAS, M.S.S.; FARIAS, C.H.A.; AZEVEDO, C.A.V. Desempenho do sistema de irrigação por aspersão, tipo pivô central rebocável. Irriga, Botucatu, v.14, n.4, p.481-491, Out., 2009.

DAVIS, J.R. Measuring water distribution from sprinklers. Transactions of the ASAE, Saint Joseph, v.9, n.1, p.94-97, Jan., 1966.

HEERMANN, D.F.; HEIN, P.R. Performance characteristics of self propelled center-pivot sprinkler irrigation system. Transactions of the ASAE, Saint Joseph, v.11, n.1, p.11-15, Jan., 1968.

HEINEMANN, A.B.; FRIZZONE, J.A.; PINTO, J.M.; FEITOSA FILHO, J.C. Influencia da altura 
do emissor na uniformidade de distribuição da água de um sistema tipo pivô central. Pesquisa Agropecuária Brasileira, Brasília, v.33, n.9, p.1487-1491, Jan., 1998.

JALOTA, S.K.; SOOD, A.G.B.S.; CHAHAL, B.U. Crop water productivity of cotton (Gossypium hirsutum L.) - wheat (Triticum aestivum L.) system as influenced by deficit irrigation, soil texture and precipitation. Agricultural Water Management, New York, v.84, n.1, p.137-146, Jan., 2006.

\section{KELLER, J.; BLIESNER, R.D. Sprinkle and Trickle} Irrigation. New York: AVI Book, 1990. 652p.

LÓPEZ-MATA, E.; TARJUELLO, J.M.; JUAN, J.A.; BALLESTEROS, R.; DOMÍNGUEZ, A. Effect of irrigation uniformity on the profitability of crops. Agricultural Water Management, New York, v.98, n.1, p.190-198, Jan., 2010.

PAULINO, J.; FOLEGATTI, M.V.; ZOLIN, C.A.; SÁNCHEZ-ROMÁN, R.M.; JOSÉ, J.V. Situação da agricultura irrigada no Brasil de acordo com o Censo Agropecuário 2006. Irriga, Botucatu, v.16, n.2, p.163-176, Abr./Jun., 2011.

PEREIRA, L.S.; PAREDES, P.; EHOLPANKULOV, E.D.; INCHENKOVA, O.P.; TEODORO, P.R.; HORST, M.G. Irrigation scheduling strategies for cotton to cope with water scarcity in the Fergana Valley, Central Asia. Agricultural Water Management, New York, v.96, n.5, p.723-735, Mai., 2009.

PETERS, R.T.; EVETT, S.R. Automation of a center pivot using the temperature-time-threshold method of irrigation scheduling. Journal of Irrigation and Drainage Engineering, New York, v.134, n.3, p.286-291, Mar., 2008.

SAAD, A.M.; LIBARDI, P.L. Qualidade da irrigação controlada por tensiômetro em pivô central. Scientia Agrícola, Piracicaba, v.51, n.3, p.549-555, Set./Dez., 1994.

SILVA, E.M.; LIMA, J.E.F.W.; AZEVEDO, J.A.; RODRIGUES, L.N. Proposição de um modelo matemático para a avaliação do desempenho de sistemas de irrigação. Pesquisa Agropecuária Brasileira, Brasília, v.39, n.8, p.741-748, Ago., 2004. 